\title{
Elementary investigation on Division of Labour. Part 1
}

\author{
Harshad Dave \\ Additional General Manager (Retd.), Gujarat State Fertilizers and Chemicals Ltd. (GSFC), Vadodara, Gujarat, \\ India
}

\begin{abstract}
If the "Division of Labour" is just a process of selecting work point in social system and net-work by a man not only for retaining self existence but to realize the living of his dream, it is too superficial analysis of a vital term of economics. Human society could evolve with the help and application of discoveries and inventions (in short - DIs) successfully applied on natural resources. It also required for material support and application of labour to secure targeted results. This process warranted a systematic coordination among application of DIs, exploration, control and regulation of natural resources, labour support for the application. Simultaneous and synchronized functioning of above three constituted a process to which we address as the classical coordination. However, the evolution of human society under the classical coordination realized with various preconditions to be complied by men.

Here it is tried to reveal the facts of social development/evolution under the process of classical coordination. The process of division of labour is an inseparable part of the classical coordination. The classical coordination is basic to evolution of human society. The original constitution of evolved division of labour with the evolution of human society under classical coordination is perfect and without any contamination of human unethical values. Unfortunately the spoiled social environment due to frequent and innumerable breaches of preconditions encouraged application of abilities of men (members of the society) in unethical ways/means. It contaminated the naturally evolved process of division of labour. The spoiled process of division of labour introduced disappointment and agony in the minds of the people that were victimized by the unethical application of abilities to favour incompetent people or to secure self interests and ultimately it resulted into a class struggle. The consequential results of contaminated process of division of labour are also discussed in short.
\end{abstract}

Key words: exchange value, imaginary line, preconditions, typical abilities, barbaric ability, natural abilities, gyp and classical coordination.

JEL Classification: A13, A14, B21, F43, F50, I24, O12, P16, P26, P48, Z13.

(C) The Author, 2018. This article is published with open access at Sumy State University.

\section{Introduction}

I find it utmost necessary to give a tentative profile of my discussion on this vital topic of economics as well as sociology. If I spell out for division of labour in very simple expression as "The process of division of labour is a set of various activities in our society that settles the fresh and incoming young generation on different work points to make their living", it is misleading. It is not that simple as it is expressed above. I have tried to discuss its implication part in following pattern:

$>$ There is an incessant flow of production of kids in human society. There are ways and means with which they are nourished to grow. They are attached to their parents with emotions and sentiments and it is natural.

$>$ The parents are with different status from wealthy to extremely poor, competent and influential in some cases while as incompetent and helpless in other cases. The potential to provide protective shelter to the kids by the parents varies case to case.

Some kids might lose their life before they attain the age of a youth.

The new / fresh young generation passes through a struggle to find a work point ${ }^{*}$. [ ${ }^{*}$ Work point is the place or position where person finds opportunity to exhibit his typical abilities and secure a reward to make his living.]

$>$ The above struggle should segregate the incoming flow of the young/fresh people for different work points depending upon potential of their warranted typical abilities as well as overall ability/competency. 
Generally it is observed that population strength of this incoming flow of youth is always higher than that of availability of work points in the prevailing social structure.

The above segregation process should, ultimately, return with 1 . A mass that got accommodated in the social system with occupying suitable work points. 2 . A mass of youth that could not be accommodated on any work point 3 . A mass that lost their survival in the subject struggle.

Here it is presumed that the above process of segregation is impartial and ethical in all respect and that ensures occupation of work points to deserving people only.

But, unfortunately, it is not so in practical life of our human society and a new story starts.

Here, it is tried to study the social environment in which the process takes place. It is also tried to reveal the linkages between the process of division of labour and human characteristics. There is also a discussion on the influence of unethical applications by men on the process of division of labour as well as how such influence ultimately transforms the social system into a perilous environment that we face today in our society.

\section{Literature Review}

Veteran writers - economists, sociologists and philosophers have expressed their views on the process of division of labour. However, the subject matter of this topic is so wide and deep that it needs study and restudy to constitute our realistic comprehension for the process of division of labour with better clarity.

Thinkers of economics/sociology and philosophy have carried out a large and deep work on the topic of division of labour. However, if we go through the various works of veteran thinkers/scholars (present and past), we will realize that the region and jurisdiction of discussion on division of labour is limited to break up of a long task with series of production operation stages. Let us refer the wordings of some modern work....

"In the modern world, those specialists most preoccupied in their work with theorizing about the division of labour are those involved in management and organization. In view of the global extremities of the division of labour, the question is often raised about what division of labour would be most ideal, beautiful, efficient and just."

"Size, cost, and the development of new technology are factors that have influenced job specialization structures in the modern workplace. The cost of job specialization is what limits small organizations from dividing their labour responsibilities, but as organizations increase in size there is a correlation in the rise of division of labour."

"In general, in capitalist economies, such things are not decided consciously. Different people try different things, and that which is most effective cost-wise (produces the most and best output with the least input) will generally be adopted. Often techniques that work in one place or time do not work as well in another. This does not present a problem as the only requirement of a capitalist system is that you turn a profit."

I agree with the thoughts and presentation given on division of labour by present and past thinkers/researchers but, here, I have tried to throw light on some such aspects of the topics in this article that are not given a justified place in the above discussions. I appeal to the young and fresh scholars of political economics to explore the innovative thoughts in this article still further in detail.

\section{Acquaintance with some terms used in this article:}

It is necessary that reader of this article should be aware of some terms that will be used onwards to this article frequently at different places.

Classical coordination. It is simple to say that intellectual power of man brought various discoveries and inventions (in short - DIs) in return. Our human society developed on them progressively by way of social evolution. However, it is not that simple. The DIs cannot have effective role, if they are not applied appropriately and commissioned practically to surmount the challenges and hindrances against the social productivity and development. It might be explained as follow:

There are people that make new DIs. There are people who make effort to find out remedy of various social issues and challenges with the help of the DIs.

The inventions require material support to manufacture the invented devices for the predetermined purpose. If scissor is an invention, then iron is a material support and iron ore is the natural resource. 
There must be natural resources competent to support existence (living) of people as well as to satisfy their various needs and wants. The same might be exploited only with the help of DIs.

$>$ There must be minimum required labour power (physical or /and intellectual) that is inevitable for the successful application of the DIs to exploit the natural resources. It is processing of iron ore to manufacture the scissor.

Above four points warrant a systematic coordination among them to make the process of exploitation of natural resources successful, productive and fruitful. We shall address the above coordination as "classical coordination" throughout in this article.

Work point: We all are aware that a man/woman adopts any type of working that might reward him/her some resources that are competent to support his/her making living as well as help to satisfy his/her needs, wants etc. A position where the activity that satisfies the above target of making living and desire to satisfying needs, wants etc is addressed as "work point" in this article. In other words, the place and profile of business activity or employment that reasonably ensures survival in the social system.

Preconditions. When man adopted the new method/system of classical coordination to manage resources of survival, it did return with a bulk production of the same but the system of classical coordination for lucrative production of means of survival and assured higher rate of exploitation of natural resources compelled man to make a specific living system. This living system was not only differed (distinguished) from the natural wild life system but some of the methods and ways of the functioning of the system were contrary to and against the well established natural laws of wild life system also. The initiation of living in a group with a distinguished system was nothing but the foetus of human society. It was challenging to establish a separate system just to adopt and make the classical coordination successful; however, it could be realized by way of social evolution. If we travel along time line we might realize that progressive evolution of human society emerged with a social system that was (and that is) getting distinguished from the wild life system. But this gain or success was not free of some liabilities, but it was with various preconditions.

The human social system evolved under the classical coordination with some untold and unwritten preconditions only. The evolved social system might function healthily only if the subject preconditions are followed and honoured legitimately. If the preconditions are violated what are the likely consequences is the field to be explored by the young scholars of present time, and if they explore the same, I am sure they will reveal the strong linkages between the present social issues and breach of the preconditions as well as actors behind them.

The above preconditions were all the laws and rules of the society for its good functioning of social system. The preconditions were to ensure the logical and ethically good precedents and established practices, mannerism, self discipline and social discipline, maintaining good moral in our acts and honouring ethical values while dealing with others etc. They are the explored preconditions about which we are talking. The classical coordination, preconditions, breach of the preconditions (deliberate or by default) and the consequential effect of the breaching on the overall functioning of the social system have profoundly influenced the process of evolution and development of human society. The breach in preconditions has caused substantial deformation in the performance and functioning of our social system. We shall frequently come across the word preconditions in this article and it should be comprehended as explained above.

Imaginary Line: There is always a flow of kids that are born and grow up to a mature age in human society. This is true for wild life system also for the entire creatures. No doubt a part of kids loses their lives during the growing. However, the survived and grown up kids reach the age at which they are supposed to make their living without a shelter and aid from their mother/parent. The age at which the kids are supposed to become self sufficient is more or less well determined by nature in wild life system for all the creatures including human. The length of maturity age varies species to species. Here we draw an imaginary line in human society where the kids are born and proceed towards the imaginary line with their growth and reach the imaginary line as soon as they attain the prescribed self reliant age. The crossing of the imaginary line is a zone and while passing through the zone, the process of Division of Labour takes place.

Typical abilities: Before ape came into existence as a man in a human society, he was among one of the wild species. All the wild creatures are with a set of abilities to make their living, like wise an ape was also with a set. These abilities are showered upon them by nature and it varies species to species and also varies as per different geographical conditions at various places on Earth. We might address these abilities as " $a$ set of 
natural abilities". The ancestors of man were also with a set of natural abilities. The classical coordination resulting into progressive evolutionary development, ultimately, emerged with a social system different from wild life system. The evolved social system provided an environment to man when he had to bring out some different types of abilities that were, otherwise, not recognized by wild life system as a mean to make living and secure survival, for example... carpentry, cobbler's work, smithing works etc.

These typical abilities were already in man but they were in dormant condition. When there was wild life system around man, there was no scope that the typical abilities in dormant condition might be brought out for their application. It was the process of classical coordination that generated an environmental flux around primitive people that awakened the dormant typical abilities to apply as warranted by the work points. So, the typical abilities are not recognized by wild life system as means to make living. It is exclusively the human social system that recognizes them as means of making living. It is the reason why the items in the list of recognized typical abilities changes as the socio economic formation changes under the progressive up gradation of classical coordination.

Stress and strain. The human social system is an evolved social system. The readers of this article should not presume that breach in preconditions immediately brings a catastrophic collapse of the prevailing social system in no time. Such a sturdy evolved structure cannot collapse like a palace of play cards. The breach of preconditions creates indignation in the victims. It generates distrust on the social system among the people, retaliatory feelings and many other harmful developments like hurt and spoils to the overall moral of the people. The above spoiled moral reflects in the interaction of the people when they deal with each other as to share inevitable activities necessary for making living. It ultimately causes stress and strain in the minds of the people.

\section{An introduction to the social environment where process of Division of Labour takes place:}

Division of labour is one of the most vital topics of economics. Perhaps one might agree with me, if I say "Division of labour is the preamble of economics subject".

The question "Why man developed and hyena did not?" might be correctly replied by God only. However, there is nothing wrong, if any one presents his views on the same issue. Summarization of such views might lead to a correct and logical reasoning. That might prove to be the nearest reasoning to the fact.

It is difficult to answer why man is so intelligent compare to other living creatures of the planet. However, sometimes I fear in my mind that it might be an illusion of our mind where we conclude ourselves most intelligent while the souls from the heaven might be laughing at the illusion.

Anyway, coming back to our discussion, the primitive man had some distinguishing methods and devices that were not with him when he was born. For example, if a cub of tiger is born, its abilities compare to a young tiger are limited or almost nil. However, it is sure that the same abilities are going to develop in the cub as it grows older provided it does not face any mishap in its childhood life. It is ensured that natural abilities that are evolved in specie will be there at appropriate time (age) in any of the animal. The potential of such abilities might be different among animals of same species. Man is the only animal that has his own natural abilities and the same are upgraded (supplemented) with external devices, facilities, conveniences etc with the help of DIs.

A heavy stone might be impossible to be toppled by a man. But the man might topple it with the help of a long wooden tree branch applying leverage to the stone. This event of stone toppling is not that simple as it appears to be. If we analyse it closely, it has proved that a man can do such a work that is beyond his natural abilities showered upon him by the God. It has taught to us that the man can enhance his abilities with the help of knowledge, experience, suitable material support and application of the same. The combination of above potentials creates fair chances to make preparing such physical devices successfully. Ultimately, it returns with achievement and realisation of such results/things that, otherwise, would not have been realized applying his natural abilities exclusively for the same. The above discussed point is vital for detail study of division of labour. There is one more point that has grass root influence on division of labour and it is population growth. Let us discuss it.

It is a natural fact to have an attraction towards opposite sex. The act of satisfying sex generally yields with population growth. If we go to natural life (system) only, the nature has arranged such a net work of living kingdom that a balance in population gets maintained within the stable limits only irrespective of population 
strength born. One can confidently say that in the history of Africa, there was not a single epoch when population of lions surpassed the population of wild beasts. The geographical situation, climatic conditions and opportunities to react with them always maintained the limits of population growth of any species of animals (including man till he was primitive) within a particular domain.

Further to this, realization of boosted abilities over and above the natural abilities in man had first time opened a road that was going to lead mankind to a platform on which today we stand. However, this journey was not that easy. But, it realised also. If we further analyse the example of leverage given to the big stone above, it should attract our notice that reality of toppling a stone beyond the capacity of man with natural ability warranted following,

$>$ Need to arrange a log-branch of tree as beam.

Need of an another log piece to put as fulcrum.

Knowledge of assembling the device in a way to ensure the anticipated / targeted end result (here toppling of the stone).

Operating the set device and application of required force.

The task to topple the stone beyond natural ability of man could be realised but it warranted knowledge or idea of creating a device as well as operating it, essential material of some defined specification for the above device, application of force to operate the device to bring the end result, judgement, and intellectual power to assemble the device correctly.

It was a very long epoch when man enjoyed plenty of benefits of science without exploring its scientific principles but utilized them only on practical results and experience. Further to this, man could introduce necessary upgrading and improvements also by trial and error method. Then after, some curious minds worked on the same to explore the reasoning, principles and laws working behind the same and that subject was recognized as science. Anyway, this process, though with slow progress in initial epoch, received more and more momentum as the achievements also helped to reveal new DIs.

Man made his living in a group in very primitive stages. The activities and efforts put up by the group to make survival and to secure safety were founded on natural abilities of the man. But, it was also true that efforts made for survival exclusively on natural abilities had limitations compare to the same if made through the enhanced productivity to be developed by using facilities, devices and necessities developed on the application of DIs. This limitation was one of the prime parameter that was curbing population growth inside the group living.

Introducing the "Classical Coordination" and revealing the status of "Division of labour" as one of the inevitable constituent of the "Classical Coordination". We are aware that DIs are made by human. The achievements of DIs did not hold only in a form of knowledge but it was applied on resources of nature to produce commodities, goods and things to manage living and to satisfy various needs, wants and yearns/lusts etc. It means the knowledge had no return if specific natural resources are not explored for the application of the knowledge. Moreover, the application of knowledge of DIs on natural resources warranted for labour, typical abilities, skill and dexterities to realize the targeted production (commodities, goods and things). The knowledge, the natural resources (on which knowledge might be applied) and the labour power (physical and intellectual) created a potential situation and golden hope to make living as well as to satisfy needs, wants and yearns.

But it compelled men to constitute a system of making living with some determined rules, customs, precedents and laws that ultimately turned into some preconditions that are to be obeyed, complied, honoured or followed by the members of the habitation if they want to ensure benefits of application of the above mentioned knowledge and it is Classical coordination. Ultimately, this system was evolved in a form of human social system with all the inevitable preconditions. The systematic coordination among the explored knowledge, the respective natural resources and the application of labour force became an inevitable and prime prerequisite for the survival or existence of human society and it evolved on the same line. The preconditions that were born along with the up gradation in classical coordination and that brought the evolution of the human society, ultimately, became the controlling and regulating parameters that are responsible for functioning and performing of the social system. 
Here is the time when division of labour emerged on horizon but at the rate of evolution as well as in level of socio economic formation of the prevailing time. I point out here to the readers that the progress in status of fishing methods - "fishing by wooden spear" to "fishing with net \& rafter" - might have taken few hundred or a thousand years, and perhaps more also. It is not possible to elaborate it in wording. However, it is essential to verify the various aspects that have grass root influence in the further evolution of human society by these changes. The further journey was not in line with the evolution of other animals. I have tried to analyze the fishing activity here but the same holds good for the task in production of other commodities also, but that might be in different pattern. Here, if we sharply analyze the various activities and their distribution among people participating in the task of fish catching from deep water site with the help of fishing net and rafter, we will realize that there are many activities from raw materials for rafter and fishing net to operation of fish catching.

The human society of the time and even present society is founded on various other tasks also like agriculture production, processing of jungle products, animal husbandry, poultry farming, processing of other materials, metals and minerals etc, and it (the pattern of scrutiny) equally holds good for them also. We will find in the above activities that there are numbers of work points and a demand of typical abilities on each work point emerges when the classical coordination takes place during the above productive activities in a society. If preconditions of the constitution of the society are to be complied and the classical coordination is to be maintained, we are required to employ manpower with different typical abilities at various work points in the above scrutinised activity list (fishing with net) as an inevitable proviso. An attentive study of the process that perpetually puts appropriate men with warranted typical abilities on various work points constitutes a subject that is known as division of labour.

Origination and progressive emerging of division of labour. Please refer: "Page 56 Economic and Philosophic Manuscripts of 1844. Third Manuscript" by Marx.

It starts with... Adam Smith: "This division of labor [...] is not originally the effect of any human wisdom $[\ldots]$. It is the necessary, [...] slow and gradual consequence of [...] the propensity to truck, barter, and exchange one thing for another. [...] This propensity" to trade is probably a "necessary consequence of the use of reason and of speech $[\ldots . .$. ".......

"As it is the power of exchanging that gives occasion to the division of labor, so the extent of this division must always be limited by the extent of that power, or, in other words, by the extent of the market....."

Ends with In an advanced state of society "every man thus lives by exchanging and becomes in some measure a merchant, and the society itself grows to be what is properly a commercial society." (See Destutt de Tracy [, Élémens d'idéologie, Paris, 1826, pp. 68 and 78]: "Society is a series of reciprocal exchanges; commerce contains the whole essence of society.") ... The accumulation of capitals mounts with the division of labour, and vice versa."

If we go through the above views of Adam Smith we shall learn that Smith links division of labour with exchange process. I find it expedient to clarify in this regard to the reader. In fact division of labour is a part of the classical coordination. The classical coordination emerged before human society was surfaced out. Before human society came into existence, there was a group living in a habitation by men. They did use various empirical discoveries as well as crude inventions of the time in the habitation for making living but there was no exchange process in the living system of the habitation. That is why such habitation cannot be treated as human society, but the classical coordination was of course there in the group living, but it was too primitive.

It was the habitation making living without exchange process but with the classical coordination. The time period between the first group-living that came into existence and the same group living progressively converted into social system by adopting exchange process as a prime and inevitable way of running productive system might not be a short one. It might have taken thousand years or still more. There was incessant addition of fresh DIs in such group living. A stage might have reached when it was found impossible to upgrade the status of the classical coordination without introducing exchange process in day to day dealing and without making association among different people in productive system to incorporate practical applications of the fresh DIs. When exchange process was introduced in productive system as above, it introduced innumerable unwritten and untold preconditions also in the system.... the group living habitation that was now progressively getting converted into a human social system from its previous status of group living. 
So, it is utmost important to know that division of labour is far senior to exchange process on time line of the evolution of human society. Division of labour did exist since long before exchange process came into existence. Of course, it is true only if you agree that there is a difference between group living and human society. Human society came into existence only after exchange process was adopted in its productive system; otherwise, it was a group living only. Second vital point to be noted here is that it was impossible to upgrade prevailing productive system without adopting exchange process as discussed above.

Men of the time realized the fact that there should be different group/people that should take care to make rafter, oars and net and they should also maintain them. While as other group will go for fishing. Even there also, some people controlled the navigation of the rafter and other operated the net to trap fish. However, those who accepted to go to fishing they might be competent for making accessories and conveniences (i.e. rafter, oars and net etc.) also. It might also be true that a man might be more skilful, alert and clever in navigating a rafter even in odd condition; however, he may not have better hand on making rafter and net or recognizing and collecting necessary material from surrounding jungle for the same.

There might be people in the group who are excellent swimmer and diver in the water and they worked to operate the net skilfully while other skilfully navigated the rafter in support. This all activities demanded various typical abilities and it was the process of scrutiny from the total group of men to employ appropriate people at different work point depending upon potential/quality of their typical abilities suiting to the respective work point. This process is the process of division of labour. Of course, there is nothing new in it. However, the distribution of the activities and production yield were to be carried out in compliance of many untold and unwritten preconditions and this fact has not come into discussion/debate by the present and past thinkers. As far as distribution of activities is concerned, it constitutes division of labour and one of the prime and vital preconditions is it should be impartial, without favour and it must give priority to the people with higher potential of typical abilities. We shall discuss if this precondition is practically complied or not. Also, its consequential effects will be discussed at appropriate place in this article onwards.

Existence of "The weak on opportunity" and "The competent on ability" in a society. Various creatures exist in wild life system. Generally it is believed that they maintain their existence because they are competent. There is nothing wrong to believe so. However, we are discussing such a topic of political economics where a precise understanding in the detail fact is solicited. If it is true for wild life, it is equally true for man making living in social system also.

It is a mistake to believe that a creature living in wild life is alive because it is competent one. If its existence is on opportunity, it means, the animal has not faced the moment of a fatal challenge to its ability, and failing while facing it will diminish its existence. Even though, it exists. It is likely that it has not encountered a challenge from the system that might put its weak abilities on test, and that is why it is alive with its other competency to make living. If this is a fact, the creature will survive till the subject occasion of the test is not encountered.

If a deer is injured on its one leg with all the possibility of easy recovery within a span of a short time, during the time while it gets recovered, its survival is on its fate and opportunity. If the deer is spotted by a leopard, hyena or wolf etc - before it gets fully recovered - its death is certain as its vital defensive ability (fast running) is under recovery. Here the injury does not permit it to run away for an escape. Under the circumstances, its survival is on opportunity. If it is fully recovered from the injury before getting spotted as above, again it has possibility to defend itself with its natural ability of fast running. There are fair chances; it will again maintain its existence on its ability instead of opportunity. This might not be single unique case. We are aware that every creature has a set of various abilities in different slots and a serious weakness in any slot of ability will be threatening only when occasion and event arises to challenge it. It means, if we take any specie of living creature, there is a part of population strength that exists on opportunity. Many of them do exist but on opportunity only. It is true for primitive men also. Keeping above fact in mind, let us analyse its (its means presence of weak people on opportunity) effective role in human society.

It is a fact that the knowledge of working in combination and compliance is not the exclusive discovery of man only. We might observe the same practice in animals and insects also. But the position/status of working profile remained more or less stagnant as seen in the animals/insects since thousands of years or more. However, the same profile found progressive changes in a group living of men. A primitive human society has something still further than the above achievement. While in the case of man in the society, he surpassed this status (status of "working in combination and compliance") and entered into such working style in the group 
that differentiated man from animal. Moreover, the new status of working profile cropped up with a perpetual and spontaneous up gradation and introduced with new changes in the social system. We shall examine the same changes also. [There are numbers of various changes but we shall examine the only one that concerns to the subject matter of this article most.]

I personally believe, there is always a mass present and alive in any species in wild life that exists on opportunity and gets smashed if opportunity gets diminished. The proportion ratio between "a mass (weak) on opportunity" and "a mass (competent) on ability" floats between two definite limits of a domain for any species in wild life system. It is applicable to human also till men were in primitive living pattern. As the group habitation got converted into human society with exchange process and the society slowly developed with productive system, the above discussed proportion between the two (existence of "the weak on opportunity" and "the competent on ability") also got disturbed. It emerged with its new dimensions in the society and the ratio was changed. The new limits of the domain of the above mentioned ratio between the two in human society got founded on the then prevailing socio economic formation of the time. Not only that, but, compliance to the preconditions evolved with the prevailed socio economic formation was the prime foundation for the retaining of the new limits. As the breaches in the preconditions crops up, it returns with a reflective stress and strain on the social system and its functioning causing pressure to change the above limits. The area of discussion on this topic is wide one but we shall discuss the point that only concerns to the division of labour. Let us glance on "how does it happen?"

Protective coverage to kids and its naturally prescribed length of time. One will agree that nature has put some protective provisions to the kids of every species as the kids do not have competent (developed) defensive system for self protection for the survival and lack of ability to manage food from the outside world. However, the protective shield progressively vanishes as the kid attains self reliant age, when it (kid) is supposed to become self sufficient. This is true for all the animals including man also. However, there is a vital difference between man and animal on this issue.

The kids of the animal have to maintain their survival on reaching to a self reliant age with the set of natural abilities given to it by nature/God. Also, more or less the age of maturity is fixed by nature species to species and there is a span of time within which they have to learn making living on their own. This span/period is also more or less fix in any specie in wild life system. Creatures other than man can provide such shield of protection to their kids only for a naturally prescribed length of time and with their natural abilities only. As soon as the kids attain naturally defined age of maturity, they are slowly and solely forced to switch over to manage their needs of survival from the surrounding world through their self efforts. Of course this transformation of dependency from mother/parents to self sufficiency is progressive during the age of subject transition.

As we discussed above, the animals are with their natural abilities, they do not have any help of DIs that might boost up their abilities. Man made many inventions based on discoveries made by him or by his ancestors. The animals did not make any inventions due to its intellectual limitations or reasons unknown to us. The DIs helped man to boost up his overall ability in many folds. Kids of the man also benefited by the boosted abilities founded on DIs. The population control of animal species was substantially being regulated during the period when kids were born and grown up to the age of self sufficiency. Balance population control of animals was getting regulated during the life span of an individual animal after attaining self reliant age and this was mostly seen during the struggle for survival and events of accidental opportunities. The abilities of grown up kids of animals always remained under test for the survival. The time period between the termination of mother's (parents) support and getting settled with the outside world for making living proved to be a harsh and shrewd filter for the test of ability/competency to survive in wild life for the fresh youth of the kids. It genuinely assured successful crossing the above kids-age-zone only to competent mass from the kids and entering the area of the animals with self reliant age.

But it is not the same pattern with mankind and that of their kids in human society. Here, above discussed "ability and opportunity" plaid a vital role for maintaining existence. This was applicable to man specie also. However, it was first time in the history of the world when kids of man were getting benefited by the support/help of DIs for maintaining their survival, that too beyond the naturally prescribed time limit. Benefits of DIs returned with an overall advantage to produce means of survival and resources for making living easy and that ensured their (resources to survive) availability in surplus. These all the benefits were partly and indirectly 
helping their (men's) kids also with extra protective shield extending its above discussed natural limits. Kids of animals did not find such extension in above limit and did not enhance protection with boosted abilities.

The above extended protective shield to man's kids returned with three consequences that are vital to many social issues till today and it has a grass root concern with the division of labour.

$>$ It provided the above discussed protective shield to their (men's) kids for an indefinite length of time. This was possible only because parents had sufficient commodities and resources on hand even after their own consumption. It introduced an assurance to parents to cultivate a mind-set that possession of surplus resources (wealth) might positively ensure satisfaction of their sentiments towards their kids to protect them for an indefinite length of time. The naturally prescribed time limit of protective shield was apparently violated. The parameters that influenced the new limits were evolved with prevailing socio economic formation.

$>$ Let us divide the path from birth of a kid to the day when it becomes self-sufficient into two parts. One path is from birth to the age when its naturally prescribed self reliant age commences. Second path is the period of transition from the day its attempts starts to come out from the dependency on its parent to the day of established self sufficiency. The natural process of destruction of incompetent youth (kids) became inefficient and mostly abortive as the extended protective shield and boosted abilities due to DIs came to rescue. This is true for both the path as above. As a result, there was a mass of incompetent kids that survive and make living for an indefinite length of time on parental support only.

$>$ The ratio between competent and incompetent men making living on opportunity changed (i. e. ratio between existence of the weak people on opportunity and the competent people on ability). The trend of change in the above ratio proves that the strength of people incompetent for making living in wild life increases as the socio economic formation gets up graded. It means.... as our society developed with the use of more and more DIs, the population strength of people incompetent to make living in wild life grow more and more and they make their survival on the typical abilities that are required at various work points.

One more point, the death ratio between "Total born in any specie of animal" and "The numbers (count) of them that survived and reached to self reliant age" remains more or less uniform within an established range only leaving some exceptional circumstances and occasions for a temporary period in wild life system. But, the same uniformity does not hold good in the case of human social system due to the protective shield. The above ratio became larger one because of higher survival rate of the men's kids with the above protective shield.

[NB: I should point out at this stage to the reader that our basic topic of discussion is "Division of Labour", and the matter discussed above and onwards are the most vital aspects that plays key role in the constitution and concern of "Division of Labour". The discussion is not diverted from subject matter of this article.]

Looking into "How did the influence of division of labour commence?". The number of persons (strength of population) that reach to self reliant age enhanced in human society as discussed above. The esteemed love (sentiments) of a mother or parents for their kids is a natural course. The determination of parents protecting their own kids is exceptionally high. There are innumerable examples, events and witnesses confirming that these emotions might lead a mother to risk her life also to make her kids safe. This is true for almost all the species of animals, including man. The love towards kids by mother/parents does not get influenced by any of their (kid's) weaknesses. Rather, if I am not mistaken, it is my impression that a mother loves her weak kid more. When it is a natural course and a fact it can never be challenged by any philosophy. It must be accepted as a fact.

However, nature and its rules have no relation with the quality or potential of the emotions of mother/parents. Shrewd implementation of natural laws and emotions of parents at high potential to protect their kids create a conflict between the two big - the natural law v/s natural emotions. The natural laws and emotions of parents both are nature's product only and both are in conflicting. However, outcome of the conflict between two up holds the superiority of the natural law in most of the cases baring some exceptional cases. The defeated parents strive for some remedy to make it possible to protect their kids even against the natural laws. This struggle between two creates a flux of "demand for remedy".

Further to this, the process of survival in jungle life is so challenging that it becomes impossible even for parents (animals or wild men) also to devote anything for their kids after they attain age of self sufficiency. When man managed to boost up his ability with the help of DIs, his natural emotions encouraged him to 
protect his weak kids that are incompetent to stand against challenges of the time. Of course, this was in violation of established rules of nature/wild life. The combination of "emotions towards kids as nature's gift" and "defeating of nature's rule of fittest the survival" with the help of boosted abilities facilitated survival of those kids that would have, otherwise, lost their survival due to their weaknesses. So, the enhanced abilities of parents based on DIs provided an opportunity to protect weak kids during their journey from birth to self reliant age. It means a weak mass reached to self reliant age. When such kids attain their self reliant age, the question of their survival on their own, what so ever the abilities are with them, became a challenge for them (for kids) as well as for their parents who were still attached with emotions towards them.

[I request to the readers to refresh them with my article "Ability- the spine of Economics"- the article written by me [URL: https://www.academia.edu/36050375/Ability The spine of economics]. I do not repeat the same hear and take the base of those views here. This will help them to be clearer.]

When we refer that a person is weak, it is tacitly to be understood that his weakness is "lack of ability for something". The absence of ability for doing something does not mean that he is "unable to do anything". If we again peep into wild life, here also, the weak kids are proved weak against such challenges those are required to be surmounted for maintaining survival in wild life as an individual or perhaps living in a small group but without enjoying benefits of DIs. In other words, the kids were weak in those abilities that were required to face challenges in the prevailing wild life system. When parents were without any advantages of DIs on their hands, and if they had to maintain survival of their weak kids, there was no alternative, but to share from the resources of survival earned by them (for themselves) only.

The constitution of wild life-natural system is so shrewd that such sharing cannot be afforded by any animal for a longer time including ancient men also. That is why; all animals find ebb in the flow of their emotions towards their kids as soon as they (kids) reach an age of maturity in wild life system. At the same time the zeal in the matured kids for self sufficiency slowly relieves parents from the burden of nourishment.

But, now in primitive human society, the parents are with boosted abilities. They have surplus resources under their command. This lead gives them an opportunity to satisfy their sentiments towards their kids. The parents protect their kids that are with various weaknesses if the kids have to face some challenges during the life journey from birth to reaching self reliant age. It means, there are fair possibilities that some kids reached to self reliant age only under the protective shield provided by their parents. Otherwise, they might have ceased to exist. Further to this, the young kids at the self reliant age and standing at the challenges of self sufficiency is a group of young people where some individuals are weak or unable to survive on their own in the wild life system ruled by nature only. We shall name this total group as grown up young population and shortly address them as gyp further to this article.

It means that gyp incorporates both the types of people (weak and competent) in it. However, many of them (in gyp) might have other typical abilities but, unfortunately, such abilities have no effective influence to help in making living in purely wild life network in a jungle. There are fair chances to survive in a social system with the same typical abilities if classical coordination is realized. Here it is the start of "Division of Labour".

Before we continue our discussion further, I find it expedient to clarify for one development in our understanding (comprehension) about gyp. When the human society was in primitive stage, men had frequent and extensive exposure to wild life challenges while making their living. The mass of people in gyp were evaluated (tested) for their competency on the ground of their capability (ability) to face the challenges from natural wild life. However, we know that human society developed with DIs and their successful applications. These achievements put the man in superior and safe status against the above challenges. Initially people in gyp were under scrutiny if they are competent to meet the natural challenges and their natural abilities are strong enough or not. As classical coordination became more complex and up graded, the pattern of the above scrutiny shifted to verify if the people in gyp have enough warranted typical abilities or not. It slowly emerged with a demand - "if the person is not competent and courageous to fight even with a fox, it is not a point of worry, but if he has a skill and knowhow to manufacture a sward/knife from an iron ingot, he might make his living in the society." Today, majority out of us do not know tree climbing, however, we comfortably make our living in the prevailing society. Otherwise, ability of tree climbing was one of the prime ability that our ancestors/great forefathers enjoyed to make their survival.

A shifting of the natural abilities in side-column on development of the typical abilities - "A critical change and a vital turning point". Let us draw an imaginary line in an established social habitation. The 
habitation is a group with a large population. The members of the group make living on fishing, animal husbandry, jungle product collection and farming with primitive methods. The imaginary line parts between self reliant working people and mass of growing children. Here we shall take up in our discussion as if the imaginary line has divided total people in two parts as above for the sake of simplicity in our discussion. But practically all are homogeneously mixed up/amalgamated in the habitation/society. We have drawn a symbolic imaginary parting line between two in our discussion. The success in crossing of the imaginary line admits that the person has attained age of self sufficiency and competent to make his living on his own in the society. However, issue of managing survival of those weak in gyp is a challenge to the mothers/parents habiting there in the working people group ${ }^{*}$. [*working people group- means those who are already matured, established, self sufficient and making living on their own in the society.]

The readers are aware, as discussed above, that there is a demand for working people for realizing an up gradation in the classical coordination to claim benefits of new DIs. Up gradation in the classical coordination might be realized only if respective fresh DIs are ready for application, respective natural resources are on hand and surplus man power is available in gyp. Generally man has never allowed a status to prevail for a long time when up gradation is held up for an indefinite time without man power. It is the proof that human population generally remains surplus in the society. There is also a requirement of working force for all the associated activities, other than production activities but linked with to maintain and regulate the productive system in working. On fulfilment of the above activities, the synchronized working of other people might perform at the resource place in the society (fishing site, agriculture farm or animal husbandry etc). Here, in our taken up example for fishing in present discussion, the source has abundant fish available at deep water site.

The system of jungle offered man a hopeful and plenty of resources that might maintain or support men's survival provided men have supplemented abilities with the support of invented means and devices. The manufacturing of invented productive means, tools and devices based on DIs demanded for man power with necessary inevitable all the typical abilities to manage means and resources essential for his survival in the system. They manufactured the required accessories/tools or devices to support the task of securing high yield productivity by other people in the same group. This people have better competency to face the challenges looming outside the shield of protection of social system (i. e. at deep water site and on the path) and managed to get yield of fish in bulk quantity.

Ultimately it became a joint venture of high productivity by a mass of working people that incorporated people with stronger natural abilities as well as the people with typical abilities but with weak natural abilities.

Please read following points carefully.

A joint working among people of different abilities, dependency of the competent people on the working output of weak people with typical abilities

Dissatisfaction and issues emerged in method of distribution of the production/yield

$>$ Complications encountered in the event when productivity reduced below the minimum requirement with any reason etc

\section{Quarrel and crisis encountered due to the distribution pattern by the people of the society}

The above points taught men that it is impossible to make classical coordination successful without a proper regulation and skilful governing of all the activities of the developing group living system in a habitation. This was the time of birth of preconditions. Thus the classical coordination had to be realized only through the inevitable compliance of various preconditions evolved with the above development. The above developments were perpetual and simultaneous and slow enough at a rate of social evolution.

As discussed above, the social system that evolved from group living in a habitation of men of our discussion also offered an opportunity to the weak people in gyp to surviving within the then social system. But it was only possible if they have some different abilities (typical abilities) that might successfully help to realize the production of consumables and accessories inevitable for the high yield of fishing (or other product). Ultimately, the work of production of supporting accessories got closely linked with the basic production system for making survival in our social system. 
Now it was not mandatory here that all the people in the gyp must have all the natural abilities that are necessary for surviving in wild life system. If the person from gyp is missing some abilities (or they are weak) from the above list, and the same person has few typical abilities that might make him competent to carry out the associated (linked) works in the society, he has fair chances to get a share in the accrued benefits of the product (here in our example - fish) and ultimately offering him an opportunity to make living.

Moreover, the typical abilities are recognized by the then prevailing social system as a mean to make living in the society of the time. That is why, if we go through the history, we realise that a large population gets smashed as soon as the prevailing social system gets collapsed. Because, as soon as social system gets paralysed, wild life system is always in force as an invisible flux around us. You will agree that the weak people of gyp that were harbouring in the social system on typical abilities before the collapse, immediately get exposed to wild life system just prevailed at the time. Otherwise, natural abilities were pushed into side column or it found secondary importance. The set of barbaric abilities that is the prime weapon to settle difference of opinion and conflicts for interests in common emerge again to surface in the actions of the people. As seen above, many of them are not competent to face challenges of wild life system. It is the reason of loss of human life in mass when social system gets collapsed. If you ask to any migrating refugee from Syria (Year 201718), he will understand this perfectly because they have passed through the same peril.

As the society progressed with science and technology, the evaluation and scrutiny process for gyp relied more and more on verification- "If the person has typical abilities that are supportive to and in demand for the successful application of DIs in productive system of the society or not." This was a great shift of vitality and importance from the natural abilities to typical abilities. The set of natural abilities was of prime importance in the law of nature to determine the chances of survival of any animal (including ancient man) since millions of years. The natural abilities now shifted to side column. The evolution of human society with above constitution and classical coordination curtailed its importance and vitality as far as possibility to make living is concerned. The presence of typical abilities became a vital parameter to determine the possibility of survival in the human society, but the above shift made the classical coordination a life line for the survival of a major part of population making living in evolved human society. If classical coordination is jeopardised in any prevailing socio economic formation of a society, the process of determination of survival of members of the society shifts again under the control of natural abilities recognized by wild life system. Now let us come back to our discussion.

A short manifestation of the social environment and origination of parameters influencing process of Division of Labour. The process of division of labour is simultaneously evolved with the development of the classical coordination and evolution of the human society as a whole. So it is difficult (rather impossible) to find out the event and occasion that necessitated the creation of the process of division of labour. However, it is expedient to understand the social environment and circumstances in which process of division of labour burgeoned and developed. Let us peep into the same.

It is requested to readers of this article that they should always remain aware of the following absolute facts while going through this article,

Man has acquired an upper hand in intelligentsia and brain stamina compare to that of other animals.

The intelligent brain of man helped to make discoveries. The discoveries were concluded (adopted) on experience only initially for a long period. That is to say they were empirical. The concluded facts were investigated systematically to find out the scientific reasons behind them after a long time. Now in present advance society.... researchers and scientist carry out study of all the empirical discoveries systematically with scientific investigations.

The intelligent brain of man could make a combination of two or more discoveries and returned with an invention with the help of necessary material support to make the invention applicable and active.

An invention always needs material support, labour, skill, knowledge and experience if it is to be successfully applied. One should be clear in his mind that no invention can stand without physical material support. An invention is nothing but an intelligent and classical combination of one or more discoveries along with other supportive material things.

$>$ Further to this, if you carry out ultimate decomposition of any substance (chemical analysis), we generally reach to all the elements that constitute the substance (elements of constitution). Likewise, if we analyse (carry 
out cracking of) any invention (substance) on the basis of scientific rules on which it works and characteristics of all the materials used in the invention, we lastly might prepare a fundamental list of discoveries (elements) that constituted the subject invention.

The use and application of inventions assured targeted results and fulfilment (achievement) of predetermined purposes.

$>$ The use of inventions in multiple combinations with each other warranted inevitability of associated facilities like communication, storage, transportation, conveyance, regulation of the systems through institutions and public offices, systematic record keeping, handling of verities of material in bulk quantity, storage, administration and many other things leading the society to today's status. We address them as associated activities. The subject associated activities also need men power with various typical abilities to support to carry out them.

> The socio economic formation of human society reached to such a stage when application of innumerable inventions and discoveries in a series of processes became inevitable to enhance the productivity of social system. This was industrial development.

$>$ The above associated facilities, manufacturing of invented devices etc inevitably demanded services of people with various types of typical abilities as well as dexterities that were not recognised as means of subsistence for survival in wild life system in the nature.

Above development was spontaneous type and very slow. Initially small progress took hundreds of thousands of years. However, it got momentum and became faster in last few hundred years. As civilized man developed its ability to co-ordinate and co-relate among various DIs simultaneously, his capability got increased in multiple fold to explore more and more discoveries and come out with new inventions in large numbers. This offered excellent opportunity to men to gain reliable knowledge and became master in judgement. On one side, man could understand the nature more practically and realistically and acquired powerful knowledge. On other side, he also contracted many social as well as environmental problems as a result. It is impossible to narrate the profile of progressive evolution in wording in an article, however, our experience, vision and knowledge of history might help us to imagine the most probable path on which man travelled through evolution. Let us go back to the primitive human habitation to discuss further on the environment and origination of division of labour and to grasp it in realistic nature. Please read following parameters carefully.

\section{$>$ The availability of gyp as a work force.}

$>$ Devices, conveniences and facilities produced as a result of inventions.

$>$ Availability of resources of the essential material support to manufacture and operate the invented-devices.

Availability of opportunities and possibility of applying invented-devices on natural resources supportive to make living and competent to satisfy various needs, wants and yearns etc.

Above parameters support such activities that promote exploiting of natural resources and ultimately make the living of the people in the subject habitation with an adequate availability of food, shelter, conveniences, safety, comfort etc. This incessant processing in due course of time, ultimately, turn out into a society with a productive system and working people with various typical abilities, dexterities in work, special types of intellect etc. Remember that these typical abilities were, otherwise, not recognized by the nature in wild life as a mean to survive. The presence of gyp in the society made free people available in search of making their living. As such they are not supposed to give their exposer to wild life/jungle system where they might be warranted with such abilities that they are lacking. They might risk a loss of life, if done. The opportunity to apply some typical abilities on the essential works during the classical coordination remained a hopeful way for gyp to make their living. They always tried to find suitable and convenient work with the above reason. Here the activities appropriate to the typical abilities permitted them to work within the habitation area only without risk of exposer to wild life challenges. This perpetual process was supported by their parents who were making living at influential level in the society and linked with gyp through emotional sentiments that are in controversy with some natural laws (discussed before).

Further to this, it was also true that all the members in gyp were not with same typical abilities. Some of them might even lack in qualified typical abilities in various works pertaining to manufacturing fishing-net and 
rafter (as concerns to our discussion). For example, a person might not have typical ability to share work load for making a rafter or fishing net. However, he might share his physical ability to transport the material from one place to other as needed by others. Here, he does not require same intellectual potential (as he might have required while knitting a fishing-net) for carrying out transporting work.

In our example, as discussed above, the total mass of young people, crossing the imaginary line to enter and join people of self reliant age group is a mass of men/women with homogeneous mixture of competency and weakness in various abilities. We address them as gyp. It is the human establishment only where facility of selection of work on the basis of inherited and developed abilities is available through a trial and error method. Also, a fact must be noted that men can make his living with typical abilities only in human society. (* here, in our example: typical abilities are abilities to knit a fishing-net or to make a rafter from respective raw material and other labour works, but they are not recognized by natural wild life system for making living). Now, sharply analyse the following points.

The entry of the young/matured people in self reliant people zone crossing the imaginary line.

Process of getting accommodated by many of them in any of the work activities that might suit to his inherited typical abilities.

A success in developing various typical abilities (if possible) in line with the demand of the work point,

Making living on the typical abilities.

Ultimately it became a perpetual process in the society.

The above steps have constituted an incessant and perpetual process in our society. The above steps in the process have remained regulating parameters of Division of Labour that we are discussing. Here, we have discussed the example of fishing activities only, but the same pattern holds good for other productive activities like agriculture, animal husbandry and poultry farm etc also. But nature of typical abilities will be different in those cases.

Apercus of status of division of labour in different socio economic formation. Time passed, hundreds of thousands of years elapsed, and the above process (social evolution under classical coordination) slowly segregated the population (gyp) in different categories according to individual's typical abilities. This process is perpetual and prevails today also. However, it is a fact that initially this process was fair/impartial and without much influence of unethical qualities of man. The unethical qualities had to remain in dormant condition inside the man as suitable environment in the social net work was not cropped up to instigate them to come out in actions. It is inevitable requirement that there must be appropriate environment in social system to wake up apt unethical qualities in man from dormant status. The unethical qualities in man got activated as soon as appropriate social environment developed to apply them in his interaction/activities. The development of human society progressed based on more and more DIs. This development ultimately took the form of industrialization in last few hundred years. The unethical characteristics now found responsive social climate to come out of dormant condition in full flow for their application on appropriate opportunities. If one systematically studies the unethical qualities that spoil the prevailing social system, he will surely come out with following points,

There are innumerable various unethical qualities in a man but in dormant condition.

Which qualities out of the above set will get activated to mix up with actions and activities of the man depends on the prevailing socio economic formation of the society.

The set of unethical qualities changes place to place depending upon geographical as well as climatic changes on Earth at different locations. If I say in other words, the nature, properties and profile of unethical qualities in man varies with place also. Perhaps, it is because, the productive system on which the society depends is not uniform at different places on Earth.

> The set of unethical qualities generally being observed in the human actions/activities in the society before industrial revolution and that of after it will be different one. The same list is different in digital and computerised social system in latest advance society. It means the quality, profile, nature and properties of unethical qualities in man varies on time line also. 
The application of unethical qualities in actions and activities inflicted sever harm to the social system in general and it contaminated and polluted the original evolved process of division of labour.

Today, the process of above segregation - to find work point with suitable typical ability - ultimately got contaminated to such an extent that it has created a complex unrest in the developed human society. This aspect is discussed in my article "Spontaneous Processing in Human Society" [URL: https://www.academia.edu/36056300/ Spontaneous processing in human society Affiliation_Spontaneous Pro-

cessing in_Human_Society ], however, here we discuss division of labour. Up till now we presumed that the process of segregation is natural and fair only. It was presumed for the sake of simplicity and convenience to analyse the happenings of society and its linkages with the process of division of labour in the productive system of our society. But, unfortunately it did not remain natural and fair since its beginning. As the social system got up graded with the support of fresh DIs by way of social evolution the profile/pattern of the above contamination also progressively transformed in compliance to developed socio economic formation.

However, environment of social constitution, social systems and institutions did not offer fair opportunities to apply unethical abilities to influence the process of division of labour during initial stages of social evolution or past socio economic formations, particularly when the development of science and technology was very faint. As the science and technological development accelerated in last few centuries, the complex social net work offered plenty opportunities to apply unethical abilities everywhere including process of division of labour also. It does not mean that process of division of labour was absolutely not influenced by unethical abilities before industrial revolution, but it (influence) was comparatively diluted one.

The flow of incoming fresh DIs increased day by day on time line. New elements were discovered, new substances were detected, and characteristics of the more and more substances and elements were explored and recognised. Intelligent and skilful combinations of various knowledge, experience and characteristics of different material yielded with new inventions.

These inventions were born on time line against invisible social flux of a demand for high productivity, quality refinement, better extraction or exploitation of natural resources, rapid transportation, reliable communication, protective storing and so many other things as one of the prime parameter to support more population as well as to satisfy needs, wants and yearns etc of men. Moreover, the above set up warranted for many other associated facilities and systems to control and regulate the efficient and uninterrupted functioning of the invented devices and applications of the same. One can imagine the size and potential of the flow of requirement of innumerable typical abilities that remained in demand to fulfil the above task.

At the same time, the population from the minor age to major age crossing the imaginary line was getting assimilated according to the typical abilities of an individual there in gyp. However, the process of getting accommodated in line with warranted typical abilities of an individual suiting to the relative work point was not a simple one. Because, with time line, new inventions were introduced in the society, new discoveries were giving further support for inventing more. Also, inventions were inducing further version of the prevailing inventions or a completely fresh inventions that might give better results or yield replacing out dated one. This social process was perpetual and incessant. Many a time this process might have interrupted by big natural calamities like earthquake, tsunami waves, jungle fire, successive draught, epidemic and other such large scale upheavals with a loss of major or all population. But, again, the society got regularised after a span of time and once again the perpetual process as above commenced.

Based on above concept, Division of labour does not offer a free will to men. Rather it is a process that made the man to adopt activity/work suiting to their typical abilities to make living. We may link it with social evolution of human society. However, as discussed above, we have presumed that the process is ethical and fair, but in practical life it is not. Also, the profile and performance pattern of process of division of labour might not be same in two different socio economic formations as discussed before. If I say to the extent that thieves, pickpockets and other like people that make living on unlawful ways and means are also the persons who found out unlawful work points to apply their typical abilities to make living, I am not wrong.

However, if we sharply analyse the ways, technique, means and methods of their (criminals) performance, even in criminal activities in the society, we might realize that it differs in different socio economic formations. The criminals, their performance and working can never be over looked as they are also making living on the 
same and it is also a part of division of labour but resulting from its (division of labour) contamination. Requirement of elimination of crime and unlawful activities is different issue. So it is not at all fair to keep our evaluation of division of labour immune from unethical and unlawful acts.

[Here we terminate our discussion temporarily. Further discussion will be continued in Issue 3 as "Elementary investigation on Division of Labour- Part 2"]

Closing words. The process of division of labour is not that simple that we read and learn in the views of various economists/sociologist and philosophers. If we describe segregation and breaking of a long processing into various stages is a work of division of labour, it is unjust to such a vital term of economics (political economics). If we understand that distribution of work as per choices and interest is a part of division of labour, it is our too narrow comprehension of the term. The process of division of labour has grass root link with evolution of human society. "The achievement and knowledge of DIs", "recognition, exploration and command of natural resources" and "preparedness of tendering warranted form of labour" constituted a process of classical coordination. The division of labour is an inseparable organ of the classical coordination that provides for the warranted labour power for the productive system developed through the classical coordination. The source of labour power is from the grown up generation (gyp). The classical coordination inflicted some preconditions to be complied by men to make productive system efficient and successful. The breach in the above preconditions is an unethical act. The originally evolved process of division of labour was impartial and without any contamination. The sentiments of mother/parents spoiled the division of labour and that became one of the prime cause of present peril of human society.

\section{Conclusion}

The intellectual efforts of man, his contemplation on various issues returned with DIs. Man found possibility to survive with the help of applying the DIs on natural resources and tendering required labour power in a classically coordinated way.

The classical coordination realized the possibility of survival of those people who were lacking enough potential in warranted natural abilities to make living in wild life.

$>$ The system of applying necessary labour power as above gave birth to a process named "Division of labour" and the process of division of labour became part of the classical coordination.

The classical coordination also encouraged bringing out typical abilities in man. The typical abilities are recognized as a valid means to make living in the habitation for the people with weak natural abilities.

As classical coordination progressed to support survival of more population, it compelled the system of group living in a habitation to transform into a human society. But, development of constitution of human society progressed with up gradation in the classical coordination only. The above up gradation in classical coordination inflicted some preconditions to be followed.

$>$ The originally evolved process of division of labour was pure and without partiality and prejudice, but breach in the preconditions with unethical ways and means by men created environment to spoil the process of division of labour.

People applied their abilities with unethical ways and means to satisfy their sentiments, needs, wants and yearns. It not only contaminated the process of division of labour but resulted into corrupted and seducing human society.

\section{Reference}

1. Smolucha, L. Smolucha F. (2012). Vygotsky's Theory of Creativity: On Figurative and Literal Thinking.

2. Michael J. Thompson. Introduction: What Is Critical Theory? Department of Political Science, William Paterson University, Wayne, NJ, 07470, USA, The Palgrave Handbook of Critical Theory, DOI 10.1057/978-1-137-55801-5_1.

3. Lefteris Tsoulfidis. (2017). Economic theory in historical perspective, The journal of Philosophical economics: Reflections on economic and social issues, 2. ISSN 1843-2298.

4. Human Requirements and Division of Labor Under the Rule of Private Property and Under Socialism. Division of Labor in Bourgeois Society. Economic and Philosophic Manuscripts of 1844. Third Manuscript. 
5. Sraffa, P. The works and correspondence of David Ricardo. On the Principles of Political Economy and Taxation, liberty fund, Indianapolis, 1.

6. Mac Vane, S. M. (Nov., 1893). The Austrian Theory of Value. Source: The Annals of the American Academy of Political and Social Science, 4, 12-41, Sage Publications, Inc. in association with the American Academy of Political and Social Science. Available from: http://www.jstor.org/stable/1009036, Accessed: 06-06-2018 04:32 UTC.

7. Henry, G. Progress and poverty. An inquiry into the cause of industrial Depressions and of increase of want with increase of wealth.

8. Robert Schalkenbach (1935). foundation, 11 park place, New York.

9. Stenkula Mikael. (2003). Carl Menger and the network theory of money. [Euro. J. History of Economic Thought 10:4 587-606 Winter, Mikael Stenkula, Department of Economics, Lund University, PO Box 7082, S-220 07, Lund, Sweden.]

10. General systems theory. The skeleton of science, Kenneth E. Boulding, Institute for Operations Research and the Management Sciences, 901 Elkridge Landing Road, Suite 400, Linthicum, Maryland 21090, USA.

11. Halls, W. D. The Rules of Sociological. Method, By Emile Durkheim, Edited with an Introduction by Steven Lukes. 